\title{
The pathogenesis of a North American H5N2 clade 2.3.4.4 group A highly pathogenic avian influenza virus in surf scoters (Melanitta perspicillata)
}

\author{
Jasmina M. Luczo ${ }^{1}$, Diann J. Prosser ${ }^{2}$, Mary J. Pantin-Jackwood ${ }^{1}$, Alicia M. Berlin ${ }^{2}$ and Erica Spackman ${ }^{1 *}$ (D)
}

\begin{abstract}
Background: Aquatic waterfowl, particularly those in the order Anseriformes and Charadriiformes, are the ecological reservoir of avian influenza viruses (AlVs). Dabbling ducks play a recognized role in the maintenance and transmission of AIVs. Furthermore, the pathogenesis of highly pathogenic AIV (HPAIV) in dabbling ducks is well characterized. In contrast, the role of diving ducks in HPAIV maintenance and transmission remains unclear. In this study, the pathogenesis of a North American A/Goose/1/Guangdong/96-lineage clade 2.3.4.4 group A H5N2 HPAIV, A/Northern pintail/Washington/40964/2014, in diving sea ducks (surf scoters, Melanitta perspicillata) was characterized.

Results: Intrachoanal inoculation of surf scoters with A/Northern pintail/Washington/40964/2014 (H5N2) HPAIV induced mild transient clinical disease whilst concomitantly shedding high virus titers for up to 10 days postinoculation (dpi), particularly from the oropharyngeal route. Virus shedding, albeit at low levels, continued to be detected up to $14 \mathrm{dpi}$. Two aged ducks that succumbed to HPAIV infection had pathological evidence for co-infection with duck enteritis virus, which was confirmed by molecular approaches. Abundant HPAIV antigen was observed in visceral and central nervous system organs and was associated with histopathological lesions.

Conclusions: Collectively, surf scoters, are susceptible to HPAIV infection and excrete high titers of HPAIV from the respiratory and cloacal tracts whilst being asymptomatic. The susceptibility of diving sea ducks to H5 HPAIV highlights the need for additional research and surveillance to further understand the contribution of diving ducks to HPAIV ecology.
\end{abstract}

Keywords: Highly pathogenic avian influenza virus, Pathogenesis, Diving duck, Surf scoter, H5Nx

\section{Background}

Avian influenza viruses (AIVs) are ubiquitous in aquatic birds [1], particularly waterfowl, shorebirds, and gulls in the orders Anseriformes and Charadriiformes. AIVs are classified as low or high pathogenicity based on disease characteristics in gallinaceous poultry, or molecular

\footnotetext{
*Correspondence: Erica.Spackman@usda.gov

'Department of Agriculture-Agricultural Research Service, Southeast Poultry Research Laboratory, U.S. National Poultry Research Center, U.S., 934 College Station Road, Athens, GA 30605, USA

Full list of author information is available at the end of the article
}

attributes of the influenza surface glycoprotein, hemagglutinin [2]. Of global public and animal health concern is the A/goose/Guangdong/1/1996 (Gs/Gd/96)lineage of H5 highly pathogenic AIVs (HPAIVs). Infection of poultry with Gs/Gd/96-lineage H5 HPAIVs is associated with high morbidity and mortality rates, and all laboratory-confirmed human H5 HPAIV infections to date are associated with this H5 lineage [3]. Furthermore, some aquatic bird species infected with most Gs/ Gd/96-lineage HPAIVs have been shown to be

(c) The Author(s). 2020 Open Access This article is licensed under a Creative Commons Attribution 4.0 International License, which permits use, sharing, adaptation, distribution and reproduction in any medium or format, as long as you give appropriate credit to the original author(s) and the source, provide a link to the Creative Commons licence, and indicate if changes were made. The images or other third party material in this article are included in the article's Creative Commons licence, unless indicated otherwise in a credit line to the material. If material is not included in the article's Creative Commons licence and your intended use is not permitted by statutory regulation or exceeds the permitted use, you will need to obtain permission directly from the copyright holder. To view a copy of this licence, visit http://creativecommons.org/licenses/by/4.0/ The Creative Commons Public Domain Dedication waiver (http://creativecommons.org/publicdomain/zero/1.0/) applies to the data made available in this article, unless otherwise stated in a credit line to the data. 
asymptomatic whilst shedding HPAIV [4-9]. This unique characteristic of HPAIV infection dynamics in aquatic birds has likely facilitated the global movement of HPAIVs in migratory birds. In North America, there are four major wild bird migratory routes: the Pacific, Mississippi, Atlantic, and Central flyways. Migratory wild birds within these flyways maintain a diverse AIV gene pool, facilitating the maintenance, spread and diversification of AIV populations [10]. Globally, the North American Pacific flyway overlaps the West Pacific flyway, which itself overlaps the East Asian-Australasian flyway that encompasses China, Korea and much of Southeast Asia. This global flyway connection eventuated in the first detection of the Gs/Gd/96-lineage H5 HPAIV in North America in 2014 [11].

Within the Anseriformes order, non-goose waterfowl can be characterized as dabbling ducks or diving ducks based on foraging behaviours and locales. Dabbling ducks forage at the water surface where AIVs are known to persist [12, 13], facilitating fecal-oral transmission. Consequently, dabbling ducks serve as a major natural reservoir of AIVs and surveillance efforts have focused primarily on monitoring AIV populations in dabbling ducks [14]. In contrast, diving ducks forage by diving and swimming underwater. It is increasingly recognized that diving ducks play an underappreciated role in the maintenance and transmission of AIVs, leading to increased research on the contribution of these species to the ecology and evolution of AIVs [15-17]. Diving ducks have been shown to harbor rare AIVs subtypes [18], and diving ducks contributed to the emergence of North American H7 HPAIV [19]. Further, experimentally infected diving ducks can shed HPAIV in the absence of clinical disease signs [20-23], and may contribute to the spread of HPAIV. Nevertheless, there remains a paucity of information on the role diving ducks play in the maintenance and spread of HPAIVs. Moreover, the susceptibility to, and disease dynamics of emerging HPAIVs in diving ducks remains understudied.

Surf scoters are large diving sea ducks native to North America, with breeding grounds situated in the boreal tundra transitional zone across northern Canada and Alaska, and wintering areas located on both the east and west coasts of continental USA [24]. The geographical distribution of surf scoters overlaps that of migratory birds known to transmit HPAIVs. Consequently, it is important to understand the potential role of surf scoters in HPAIV spread and evolution. In this study, the pathogenesis of a clade 2.3.4.4 H5 HPAIV in surf scoters was characterized. Surf scoters were experimentally infected via the intrachoanal route with a North American Gs/ Gd/96-lineage clade 2.3.4.4 group A H5N2 HPAIV, and clinical disease, histopathology, and virus shedding are described.

\section{Results}

\section{Clinical disease}

Surf scoters were inoculated intrachoanally with $1 \times 10^{6}$ $50 \%$ egg infectious doses $\left(\mathrm{EID}_{50}\right)$ of $\mathrm{A} /$ Northern Pintail/ Washington/40964/2014 (NP/WA/14) H5N2 HPAIV and were monitored daily for clinical disease signs. Overall, surf scoters inoculated with NP/WA/14 were generally asymptomatic, exhibiting no or very mild clinical disease signs. Transient mild lethargy was observed at 5 days post inoculation (dpi), though ducks responded immediately upon stimulation. Cloacal (CL) temperatures were recorded throughout the duration of the study and were within the expected normal range for ducks: average $\mathrm{CL}$ temperatures were $40.4{ }^{\circ} \mathrm{C}, 41.1^{\circ} \mathrm{C}$, $40.8^{\circ} \mathrm{C}$, and $40.4^{\circ} \mathrm{C}$ at $0,2,4$, and $7 \mathrm{dpi}$, respectively (Additional file 1A). When expressed as percent starting temperature, average temperature throughout the duration of the study did not exceed 101.7\% (range: 97.4-104.5\%) (Additional file 1B). As all CL temperatures recorded were $<42.0^{\circ} \mathrm{C}$, it was therefore considered that HPAIV infection did not induce fever in surf scoters. Despite all ducks exhibiting transient mild clinical disease signs at $5 \mathrm{dpi}$ only, two aged birds died during the study (both were 16 years of age). One aged bird died 5 dpi (\# 629), and the other aged bird died 14 dpi (\# 635). An empty digestive tract was noted for the bird that died at $5 \mathrm{dpi}$. Gross lesions observed during necropsy of bird \# 629 included a minor esophageal fungal lesion, a fixed pupil, and corneal edema. Duck 635 that died 14 dpi had an enlarged hard spleen and chronic Candida albicans. No other gross lesions were observed in the surviving birds.

\section{Serum antibody response}

The influenza seronegative status of all birds was verified by anti-influenza A nucleoprotein (NP) blocking enzyme-linked immunosorbent assay (ELISA) prior to challenge (Table 1). At $14 \mathrm{dpi}$, all surviving ducks were bled for serum antibody analysis. All ducks seroconverted following challenge with NP/WA/14. Postchallenge serum hemagglutinin inhibition (HI) titers ranged from $2^{5}$ to $2^{9}$, with the geometric mean being $2^{6.9}$ (95\% confidence interval (CI): $2^{5.8}-2^{8.2}$ ) (Table 1 ). Post-challenge anti-influenza A NP ELISA results agreed with $\mathrm{HI}$ results, all ducks were positive for anti-influenza A NP IgY antibodies (Table 1).

\section{Virus shedding}

Shedding from oropharyngeal (OP) and CL routes of surf scoters inoculated with clade 2.3.4.4 NP/WA/14 (H5N2) HPAIV was examined. Virus titer equivalents were determined $2,4,7,10$, and $14 \mathrm{dpi}$ by real-time qRT-PCR. The peak of HPAIV shed from the OP tract was at $4 \mathrm{dpi}$, and HPAIV shed from the CL tract also 
Table 1 Serostatus of surf scoters pre- and post-inoculation with H5 HPAIV NP/WA/14 (H5N2). Whole blood was collected 14 dpi and serum was separated for antibody analysis

\begin{tabular}{|c|c|c|c|}
\hline Bird age/sex ${ }^{a}$ & Pre-challenge ELISA ${ }^{\mathrm{b}}$ & Post-challenge ELISA ${ }^{b}$ & $\log _{2}$ serum HAI titer \\
\hline $2 / \mathrm{M}$ & neg & pos & 7 \\
\hline 4/M & neg & pos & 6 \\
\hline 4/M & neg & pos & 8 \\
\hline $5 / \mathrm{M}$ & neg & pos & 9 \\
\hline $6 / \mathrm{M}$ & neg & pos & 5 \\
\hline $6 / \mathrm{M}$ & neg & pos & 7 \\
\hline $7 / \mathrm{M}$ & neg & pos & 7 \\
\hline $16 / \mathrm{M}$ & neg & nd & nd \\
\hline $16 / F$ & neg & nd & nd \\
\hline
\end{tabular}

Anti-influenza A nucleoprotein IgY response was determined by blocking ELISA using commercial kit. Serum hemagglutinin inhibition titers were determined according to the standard USDA HI procedure (Pedersen et al. 2014)

${ }^{a}$ Age reported in years. $M=$ male, $F=$ female

${ }^{b}$ neg $=$ seronegative for anti-influenza A NP IgY serum antibodies

Pos Seropositive for anti-influenza A NP IgY serum antibodies, Nd Not done, the birds had died

peaked at 4 dpi. Mean virus titer equivalents detected in OP and CL swabs at $4 \mathrm{dpi}$ were $10^{6.1}$ and $10^{2.9}$, respectively. Overall, a bimodal shedding pattern was observed for $\mathrm{OP}$ and $\mathrm{CL}$ shedding, with virus titer equivalent peaks occurring at $4 \mathrm{dpi}$, then again at $10 \mathrm{dpi}$. Virus titer equivalents detected in the second peak at $10 \mathrm{dpi}(\mathrm{OP}$, $10^{3.7} ; \mathrm{CL}, 10^{1.9}$ ) were lower than virus titer equivalents detected in the first peak. This shedding pattern may be due to reinfection, or by initial production of type I interferons (bimodal shedding patterns in humans have been attributed to type I interferon production [25]) followed by the induction of humoral immunity as the infection progressed. Virus was shed from the OP route up until $10 \mathrm{dpi}$, and only some birds shed low-levels of virus at $14 \mathrm{dpi}$. Moderate virus titer equivalents were shed from the CL route, with a pattern of shedding following that of OP. Higher virus titer equivalents were detected in OP swabs at each time point throughout the duration of the study (Fig. 1; Additional file 2A).
Additionally, area under the curve analysis revealed that overall shedding from the OP route was significantly higher than from the $\mathrm{CL}$ route (Additional file 2B), a finding consistent with previous reports characterizing HPAIV shedding patterns from experimentally infected ducks [23, 26-28].

\section{Histopathology and immunohistochemistry}

The ducks that died were the two oldest ducks in the group (16 years). One duck died at 5 dpi (\# 629, male) and the other at $14 \mathrm{dpi}$ (\# 635 female). Duck 629 had empty intestines at necropsy. Duck 635 had an enlarged hard spleen and chronic Candida albicans. On histopathologic examination, both ducks presented similar microscopic lesions. These lesions included moderate to severe multifocal necrosis in the liver, spleen, and pancreas, with presence of basophilic intranuclear and cytoplasmic inclusion bodies in degenerating and perilesional cells (Fig. 2, Additional file 3). Parenchymal
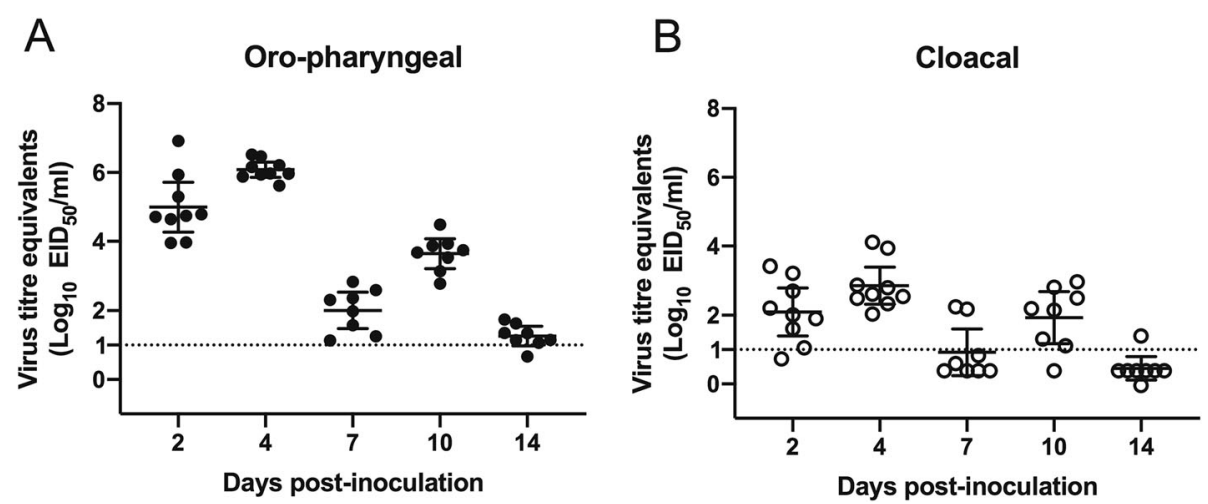

Fig. 1 Virus titer equivalents in swabs collected from A/Northern pintail/Washington/40964/2014 (H5N2) inoculated surf scoters ( $n=9)$ at 2, 4, 7, 10, and 14 dpi and detected by real-time qRT-PCR. a Oropharyngeal swabs. b Cloacal swabs. The dotted line indicates limit of detection. Error bars represent mean $\pm 95 \% \mathrm{Cl}$ 

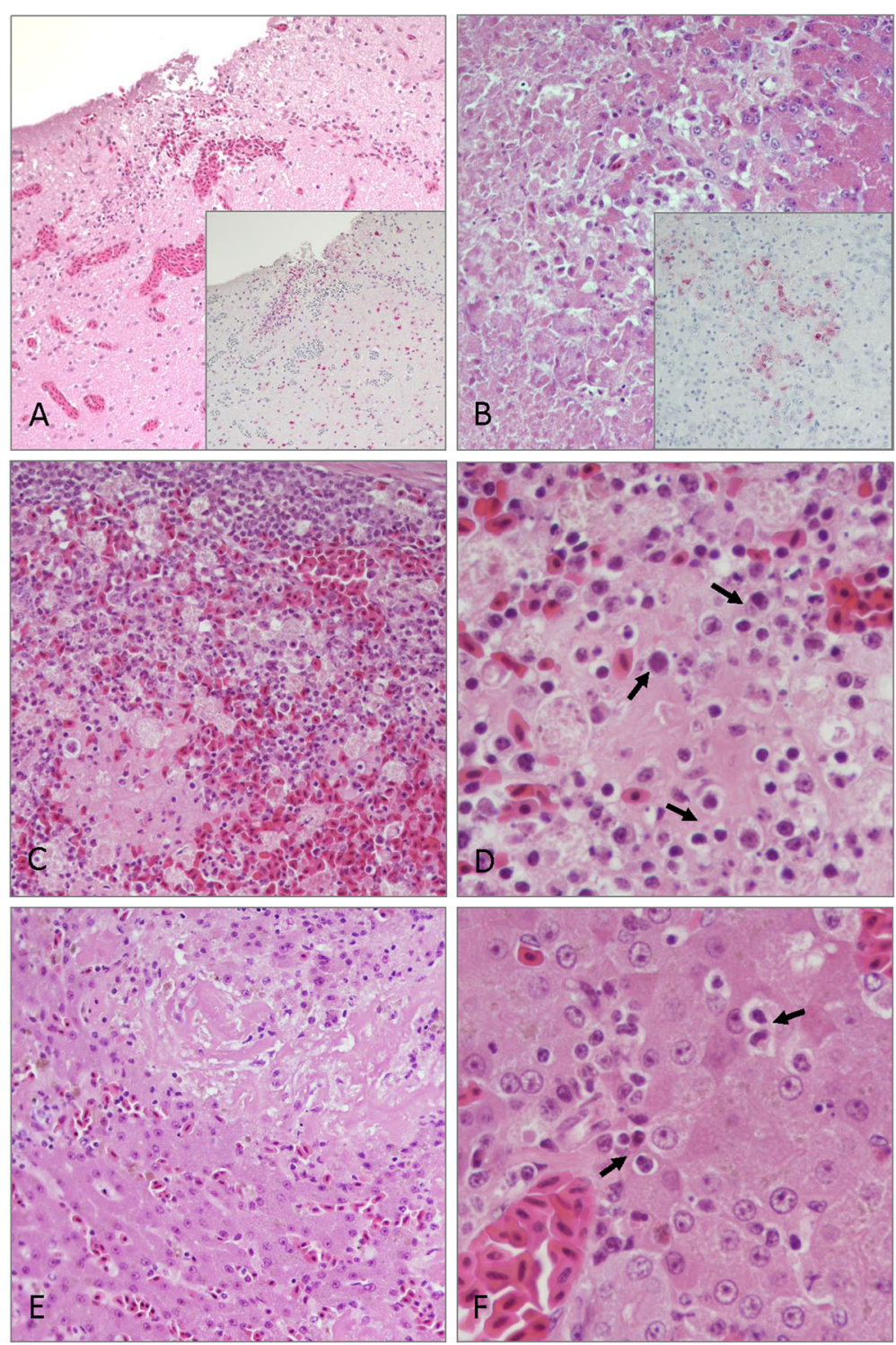

Fig. 2 Histopathology and immunohistochemical detection of influenza virus antigen in tissues from Surf Scoters inoculated with A/Northern pintail/Washington/40964/2014 (H5N2) HPAIV. a Cerebrum. Congestion and necrosis. Inset: virus antigen in neurons and glial cells (red staining), 20X magnification. b Pancreas. Acinar cell degeneration and necrosis. Inset: virus antigen in acinar cells and mononuclear cells (red staining), 40X magnification. c Spleen. Parenchymal cell degeneration and necrosis with accumulation of proteinaceous, fibrin-like material, 40X magnification. $\mathbf{d}$ Spleen. Presence of basophilic intranuclear inclusion bodies in reticular endothelial cells (arrows), 60X magnification. e Liver. Hepatocyte degeneration and necrosis and replacement with proteinaceous, fibrin-like material. $\mathbf{f}$ Liver. Presence of basophilic intranuclear inclusion bodies in hepatocytes (arrows), 60X magnification

cell apoptosis, coagulative necrosis, and serofibrinous and haemorrhagic lesions were present in all these organs. Also, in both ducks, there was mild-to-moderate diffuse tracheitis, enteritis, and mild interstitial pneumonia. In duck 629 there was also multifocal areas of congestion and necrosis in the cerebrum. In this duck, viral antigen was present in neurons and glial cells of the brain, in pancreatic acinar cells (Fig. 2), in the epithelial cells and infiltrating mononuclear cells in the trachea, in cardiomyocytes, and proventricular gland epithelium
(Additional file 3). No avian influenza viral antigen was present in tissues collected from duck 635 .

The presence of widespread inclusion bodies in the spleen, liver, and pancreas in addition to marked fibrinous-like deposits associated with necrotic lesions in the same tissues suggested that the ducks that succumbed to infection may have been concurrently infected with the herpesvirus, duck enteritis virus (DEV) (Anatid herpesvirus 1). DEV exhibits a tropism for epithelial cells of the gastrointestinal tract, and can be 
detected in CL swab fluid [29]. To confirm the histological findings, a DEV specific PCR test was conducted with nucleic acid extracted from all the CL swabs from all the ducks. Duck 635 was positive for DEV at 7 and 10 dpi, whilst DEV was not detected in CL swab fluid from duck 629. However, DEV was detected in duck 482 CL swab fluid at 4 dpi. Duck 482 was a 6-year-old duck that did not exhibit any clinical signs of DEV infection.

\section{Discussion}

The Gs/Gd/96-lineage of H5 HPAIVs has undergone extensive genetic divergence, leading to the formation of multiple genetic clades and subclades [30]. A unique attribute of the currently circulating clade 2.3.4.4 $\mathrm{H} 5 \mathrm{Nx}$ HPAIVs is the compatibility of the HA gene with multiple neuraminidase subtypes, including N2, N6, and N8 [31, 32]. Novel clade 2.3.4.4 H5Nx HPAIVs were initially detected in China in 2008 [30, 33, 34], followed by outbreaks in South Korea then Japan in 2014 [35-37]. Radiating outwards from Asia, H5Nx HPAIVs rapidly spread globally and were detected in Russia [38], Germany [39], England [40], the Netherlands, Hungary and Italy [41, 42]. The Gs/Gd/96-lineage H5Nx HPAIVs were first detected in Canada and North America in 2014 [11, 43]. Whilst one index virus from the North American Gs/ Gd/96-lineage 2014 HPAIV outbreak, A/gyrfalcon/ Washington/41088-6/2014 (H5N8), is a wholly Eurasian $\mathrm{H} 5 \mathrm{Nx}$ virus, the NP/WA/14 (H5N2) HPAIV characterized in this study is of mixed origin, with evidence for reassortment with North American low pathogenicity avian influenza viruses [44]. Although H5N8 HPAIVs continue to be detected in wild bird populations globally, the NP/WA/14 isolate is of interest because the related $\mathrm{H} 5 \mathrm{~N} 2$ lineage became the predominant lineage in North America. It was the most common of the 4 clade 2.3.4.4 variants detected in domestic birds and was the only variant identified in North American surveillance samples from wild birds after the outbreak [45], although it has not been detected in North America since 2016. However, sporadic outbreaks of a related H5N2 reassortants continue to be detected in poultry in Taiwan [46]. Therefore, there may be some fitness advantage to this gene constellation in domestic birds.

Wild aquatic waterfowl likely played a major role in the dissemination of these novel $\mathrm{H} 5 \mathrm{Nx}$ viruses in the 2014-2015 North American outbreak [31, 47, 48]. Importantly, to understand the capacity for HPAIV replication in migratory waterfowl and their potential role in H5Nx global dissemination, it is vital to understand the pathogenesis of $\mathrm{H} 5 \mathrm{Nx}$ HPAIV in diving ducks to complement what is known for dabbling ducks.

To assess the susceptibility to, and pathogenesis of the novel North American Gs/Gd/96-lineage H5 HPAIV in diving ducks, Melanitta perspicillata, were inoculated by the intrachoanal route and clinical disease and virus excretion were evaluated. Inoculation of surf scoters with North American group A H5Nx HPAIV induced minimal disease signs despite ducks shedding high titers of virus, particularly from the OP route. The propensity for H5 HPAIV-infected waterfowl to be subclinical, or display mild clinical signs has been widely described in dabbling ducks [4-9, 49], with increasing research characterizing clinical disease in diving ducks. Previously, it was shown that the North American diving duck species, redhead (Aythya americana), are susceptible to H5 HPAIV infection [23], however, HPAIVinfected redhead did not exhibit clinical disease signs, and HPAIV was shed from the OP and CL routes for up to 4 days post-challenge. Active HPAIV shedding in the absence of clinical disease has also been reported for Lesser scaup (Aythya affinis) and Ruddy ducks (Oxyura jamaicansis), two additional North American diving duck species [20, 21]. Ruddy ducks were challenged with the same North American clade 2.3.4.4 group A HPAIV used in this study, NP/WA/14 (H5N2), whilst the other diving duck species, Lesser scaup, were challenged with either NP/WA/14 (H5N2), or the wholly Eurasian clade 2.3.4.4 group A isolate detected during the North American H5Nx outbreak, A/gyrfalcon/Washington/ 41088-6/2014 (H5N8). Both North American group A Gs/Gd/96-lineage H5Nx HPAIVs did not induce clinical disease signs in inoculated diving ducks, however, both species of diving ducks excreted virus for up to $7 \mathrm{dpi}$. In a subsequent study, Lesser scaup infected with H7 HPAI Vs also did not display clinical disease signs, despite high levels of virus excretion from both the OP and CL routes for up to 7 and $14 \mathrm{dpi}$, respectively [21]. Peak virus titer equivalents detected in OP or CL swabs from HPAIVinfected Ruddy ducks and Lesser scaups was approximately $10^{4} \mathrm{EID}_{50} / \mathrm{ml}$, whereas shedding from HPAIVinfected surf scoters peaked at $10^{6} \mathrm{EID}_{50} / \mathrm{ml}$, highlighting some variation in shedding dynamics between various diving duck species. Low pathogenicity avian influenza viruses replicate primarily in the gastrointestinal tract leading excretion of high virus titers via the CL route [50, 51], facilitating fecal-oral transmission. In contrast, higher virus titers are typically excreted from the OP route of $\mathrm{Gs} / \mathrm{Gd} / 96$-lineage-infected aquatic waterfowl and poultry $[23,26]$. Surf scoters challenged with clade 2.3.4.4 group A H5Nx HPAIV shed significantly higher virus titer equivalents from the OP route compared to the $\mathrm{CL}$ route. In terms of transmission, the importance of higher virus titers excreted from the respiratory route of Gs/Gd/96-lineage HPAIV infected poultry and wild waterfowl is unclear, but is likely that oral secretions may be able to contaminate the environment similarly to cloacal secretions. Although likely dependent on the challenge virus, a meta analyses of 
virus titer shed and duration of shedding from HPAIVinfected (dabbling) ducks reported that dabbling ducks shed approximately $10^{6} \mathrm{EID}_{50}$ virus from the OP route and $10^{3}$ EID $_{50}$ from the CL route [52] and median shedding duration of HPAIV-infected ducks was reported to be 5 dpi [53]. Furthermore, virus excretion from experimentally inoculated domestic ducks with a panel of HPAI Vs suggested that shedding duration from HPAIVinfected dabbling ducks can extend for at least $7 \mathrm{dpi}$ and up to $14 \mathrm{dpi}$ in some instances [27]. Shedding patterns from HPAIV-infected diving ducks appears to be for similar to that reported for dabbling ducks; surf scoters inoculated with H5N2 clade 2.3.4.4 group A HPAIV shed similar virus titers, and for a similar duration to that reported for dabbling ducks, with virus excretion peaking at approximately $10^{6} \mathrm{EID}_{50} / \mathrm{ml}$, and virus shedding detected for up to $14 \mathrm{dpi}$. Collectively, minimizing disease impact on the host, whilst maintaining the ability to be excreted at high titers from OP and CL routes favors diving ducks as additional vectors of HPAIV transmission in the wild. Further studies characterizing the pathogenesis of clade 2.3.4.4 groups B-D in surf scoters would shed light on whether surf scoters generally shed high titers of clade 2.3.4.4 HPAIVs in the absence of clinical disease signs, or whether HPAIVs in these groups induce different disease characteristics in surf scoters.

In addition to experimental infection of North American diving ducks, experimental infection of European wild diving ducks (common pochard, Aythya ferina) with a clade 2.3.4.4 group A H5 HPAIV also resulted in subclinical disease whilst excreting high virus titers [22]. However, subclinical disease presentation in common pochards may be clade or even subcladedependent, as experimental infection with clade 2.2.1 HPAIV resulted in $50 \%$ mortality [8]. Recognizing the susceptibility and potential transmission of HPAIVs by wild birds, diving ducks in the genera Aythya and Netta have been identified by the European Union as high risk wild bird species for $\mathrm{H} 5$ infection and transmission [54].

In contrast, tufted ducks (Aythya fuligula), a diving duck that crosses to North America from Asia and Europe via vagrant migrants [55], naturally infected with H5N1 HPAIV seem to be highly susceptible to severe infection outcomes. High mortality was noted, and histopathological analysis of tissues from infected ducks revealed abundant viral antigen in multiple visceral and central nervous system organs [56]. Whilst European clade 2.3.4.4 group A HPAIVs caused low mortality in domestic (dabbling) ducks [40], to date, infection studies with tufted ducks have not been performed. However, naturally occurring HPAIV infection of wild tufted ducks lead to high mortality during the clade 2.3.4.4 group B HPAIV outbreak in the Netherlands in 2016/17 $[57,58]$. Experimental infection of tufted ducks with a clade 2.3.2 HPAIV ultimately yielded the same disease outcomes [59]. Evidence suggests that this species of diving duck may not serve in the dispersal of HPAIVs in the absence of clinical disease [59]. It is unclear whether, genetic background of tufted ducks predisposes this species of diving duck to severe disease upon infection with H5 HPAIV, a factor demonstrated to influence influenza disease outcomes in genetically diverse mice [60,61], or whether concomitant infection with other pathogens influences mortality outcomes in the wild tufted ducks.

In this study, pathological evidence for concomitant infection of some surf scoters with DEV was observed and confirmed with molecular techniques. Ducks in the order Anseriformes are susceptible to infection with DEV at all ages, though DEV-related mortality is significantly higher in mature than immature ducks $[29,62,63]$. Indeed, it was the two oldest birds that died, and DEV could have been a contributing factor. Whilst it is tempting to speculate about age-related mortality observed in this study, we exercise caution in doing so due to the small sample size. Furthermore, it is unclear whether mortality observed was directly attributed to HPAIV infection, modulated by concomitant DEV infection, or a synergism between the two viruses yielded mortality outcomes in aged scurf scoters. It is also unknown whether the concomitant DEV was an acute infection, or reactivation of latent DEV infection. Indeed, one of the aged surf scoters that died had chronic corneal edema and a fixed pupil, which can possibly be attributed to latent DEV infection since the trigeminal ganglion is a known latency site for DEV [64]. Whilst the detection of DEV was unexpected, the situation likely reflects pathogen dynamics occurring the field. Also, most of the ducks had a chronic Candida albicans infection, which is a topical fungal infection in the oral cavity. Because this condition is localized it's not expected to have an appreciable affect in HPAIV pathogenesis. Ducks with other health conditions are probably more relevant to the field versus specific pathogen free animals because it is probable that the interplay of multiple pathogens and/or the physiological stress of chronic health conditions influences HPAIV disease outcomes in wild aquatic birds.

\section{Conclusions}

Collectively, H5 HPAIV infection of surf scoters generally lead to subclinical infection whilst concomitantly excreting high titers of virus, particularly from the OP route. The capacity for HPAIVs to be shed from infected diving ducks for several days post-challenge, in the absence of clinical disease signs, likely facilitates the maintenance and potentially the long-range movement of HPAIV viruses, ultimately influencing HPAIV ecology. To further understand the emerging role of diving ducks in HPAIV transmission and ecology, HPAIV infection dynamics in diving ducks warrants further study. 


\section{Methods \\ Virus}

A clade 2.3.4.4 group A H5Nx HPAIV, A/Northern pintail/Washington/40964/2014 (NP/WA/14) (H5N2), (NCBI:txid 1,589,662; genetic characterization reported by $I p$ et al. [43]) was selected for characterization in surf scoters. Although this is not a recent isolate, this isolate was selected because it has been characterized in numerous avian species [20, 27, 28, 65, 66], which allows for comparison and may contribute to an understanding of why this isolate became dominant in North America. Virus stock was generated by allantoic inoculation of 911 day old embryonating chicken eggs. Infectious allantoic fluid was harvested, clarified by centrifugation, and stored at $-80^{\circ} \mathrm{C}$. Virus titer was determined by titration in 9-11 day old embryonating chicken eggs, and the $\mathrm{EID}_{50} / \mathrm{ml}$ was calculated by the Reed and Muench method [67].

\section{Animals and study design}

Adult surf scoters (Melanitta perspicillata) $(n=9)$ were sourced from U.S. Geological Survey Patuxent Wildlife Research Center captive breeding colonies (Laurel, MD, USA). All animal research was reviewed and approved by the U.S. National Poultry Research Center Institutional Animal Care and Use Committee. Scoter captivity and transport to Southeast Poultry Research Laboratory was approved by the U.S. Geological Survey Patuxent Wildlife Research Center Animal Care and Use Committee. Animal studies adhered to the Federation of Animal Science Societies Guide for the Care and Use of Agricultural Animals in Research and Training. Institutional review board review does not apply because the ducks are owned by the US government and approval by the IACUC is considered consent to use the ducks.

No sample size calculations were conducted because there were only 9 ducks available, so groups sizes could not be adjusted. However a group size of around 10 animals is consistent with numerous previous studies evaluating the pathogenesis of avian influenza virus in avian species $[27,68])$. When the ducks were acquired, some had a pre-existing, laboratory confirmed (by culture) topical infection of Candida albicans on their bills.

Adult surf scoter age ranged from 2 to 16 years old (Table 1), and were of mixed sex (male, $n=8$; female, $n=1$ ). Ducks were housed in modified Horsfall isolators, with single pass air ventilation, HEPA filtered exhaust, grate floors and automatically filling cup drinkers. The lighting schedule was $8 \mathrm{~h}$ dark and $16 \mathrm{~h}$ light. Food and water were available ad libitum.

Surf scoters were acclimated for 1 week, during which time pre-challenge swab and blood samples were collected. Surf scoters were inoculated with $1 \times 10^{6} \mathrm{EID}_{50}$ of NP/WA/14 (H5N2) HPAIV via the intrachoanal route and were monitored twice daily for clinical disease signs. OP and CL swabs were collected 2, 4, 7, 10, and 14 days dpi and placed in $1 \mathrm{ml}$ brain heart infusion broth supplemented with 10,000 U/ml penicillin (Sigma Aldrich; St. Louis, MO), $1 \mathrm{mg} / \mathrm{ml}$ gentamicin (Sigma Aldrich), and $20 \mu \mathrm{g} / \mathrm{ml}$ amphotericin B (Sigma Aldrich). Cloacal temperatures were recorded 0,2 , 4, and $7 \mathrm{dpi}$. All surviving birds were euthanized $14 \mathrm{dpi}$, at which time whole blood was collected for serum antibody analysis.

Due to the small sample size, only those birds that died during the study were necropsied for histopathological examination. Tissues collected during necropsy were placed in $10 \%$ neutral buffered formalin. Formalinfixed tissue samples were processed according to routine histological methods, embedded in paraffin wax, sectioned $(4 \mu \mathrm{m})$, and mounted on charged glass slides. Deparaffinized, serial tissue sections were stained with hematoxylin and eosin for histological examination or stained by immunohistochemistry using a Southeast Poultry Research Laboratory in-house anti-influenza NP monoclonal antibody (clone P13C11) to determine the tissue distribution of influenza NP antigen. Deparaffinization, antigen retrieval, blocking of endogenous peroxidases, and anti-influenza A NP immunostaining was performed as previously described [68, 69].

All surviving birds at the termination of the trial were euthanized and necropsied to evaluate gross lesions; because no lesions were observed, no tissues were collected for microscopic evaluation. Humane euthanasia of birds was performed according to American Veterinary Medical Association (AVMA) guidelines by intravenous injection of $0.2 \mathrm{~mL}$ per $\mathrm{Kg}$ of pentobarbiotal sodium solution (Fatal-Plus, Vortech Pharmaceuticals, Dearborn, MI) without sedation. This method was utilized because it was the AVMA recommended method which was reviewed and approved by the USNPRC IACUC.

\section{Serology}

The presence of anti-influenza A NP antibodies was determined by Avian influenza MultiS-Screen commercial ELISA (IDEXX; Westbrook, ME), according to the manufacturers' instructions. Serum from all ducks was tested prior to challenge and at 14 days post challenge.

\section{Hemagglutination inhibition assay}

To assess serum anti-influenza hemagglutinin antibody responses, a HI assay was performed as described previously [70]. Briefly, sera were diluted 2-fold before the addition of 4 hemagglutination units and incubated at room temperature for $1 \mathrm{~h}$. Chicken erythrocytes $(0.5 \%)$ were then added and hemagglutination inhibition recorded. End point titers are reported as the $\log _{2}$ dilution of the last HI positive serum dilution. A titer of 16 or above was considered positive. 
RNA extraction and real-time quantitative reverse transcription PCR to determine virus titer equivalents Virus titer equivalents in OP and CL swab fluid were determined by real-time quantitative reverse transcription PCR (qRT-PCR). RNA was extracted from OP and CL swab media using MagMAX-96 AI/ND Viral RNA Isolation Kit (Thermo Fisher; Waltham, MA) as previously described [71]. A U.S. Department of Agriculture standardized onestep real-time qRT-PCR assay targeting the influenza A matrix gene was performed as previously described [72]. To calculate virus titer equivalents, a standard curve was generated from a dilution series of the same NP/WA/14 stock (with known $\mathrm{EID}_{50} / \mathrm{ml}$ ) used as the challenge virus.

\section{PCR for duck enteritis virus}

To verify histological findings in aged surf scoters that died and to determine whether other ducks may have been infected, PCR amplification of the duck enteritis virus (DEV) (Herpesviridae; Anatid alphaherpesvirus 1) UL-31 gene was performed on nucleic acid extracted from all CL swabs as described above. The PCR procedure and two sets of primers (DVE-5 and DVE-7) described by Hansen et al. [73] were utilized.

\section{Statistical analysis}

Statistical analysis was performed using Prism, version 8.3.0 (GraphPad Software, Inc., La Jolla, CA, USA). Total virus titer equivalents shed from the OP and CL routes throughout the duration of the study were compared by a mixedeffects analysis followed by Sidak's multiple comparisons post-test. Area under the curves were compared using an unpaired $t$-test. Error bars represent mean $\pm 95 \%$ CIs.

\section{Supplementary information}

Supplementary information accompanies this paper at https://doi.org/10. 1186/s12917-020-02579-x.

Additional file 1. Cloacal temperatures of A/Northern pintail/ Washington/40964/2014 (H5N2) inoculated surf scoters $(n=9)$. A) Cloacal temperatures at 0, 2, 4, and 7 dpi. B) Cloacal temperatures expressed as percent starting temperature.

Additional file 2. Comparison of virus titer equivalents shed from A/ Northern pintail/Washington/40964/2014 (H5N2) HPAIV inoculated surf scoters $(n=9)$. A) Mean virus titer equivalents detected by real-time qRTPCR in OP (closed circles) and CL (open circles) swabs collected from NP/ WA/14 (H5N2) inoculated surf scoters at 2, 4, 7, 10, and 14 dpi. B) Area under the curve analyses of total virus equivalents shed from $\mathrm{OP}$ and $\mathrm{CL}$ routes throughout the duration of the study. Error bars represent mean \pm $95 \% \mathrm{Cl} .{ }^{* * *} \mathrm{p}<0.0001,{ }^{* *} p<0.01,{ }^{*} p<0.05$

Additional file 3. Microscopic lesions and viral antigen distribution in tissues from surf scoters intrachoanally inoculated with $\mathrm{A} /$ Northern pintail/Washington/40964/2014 (H5N2) and sampled at 5 (bird \#629) and 12 dpi (bird \#635).

\section{Abbreviations}

AIV: Avian influenza virus; Cl: Confidence intervals; CL: Cloacal; DEV: Duck enteritis virus; dpi: Days post inoculation; EID 50 : 50\% egg infectious dose; ELISA: Enzyme-linked immunosorbent assay; Gs/Gd/96: A/goose/Guangdong/
1/1996; HI: Hemagglutination inhibition; HPAIV: Highly pathogenic avian influenza virus; NP: Nucleoprotein; NP/WA/14: A/Northern Pintail/ Washington/40964/2014; OP: Oropharyngeal; qRT-PCR: Quantitative reverse transcription PCR

\section{Acknowledgements}

We gratefully acknowledge Scott Lee, Jesse Gallagher, Roger Brock, Anne Hurley-Bacon, and Jefferey Sullivan for technical assistance, and Glenn Olsen, Sharon Peregoy, and Randall Mickley for prep and care of scoters. We also thank Rebecca Poulson, Southeast Cooperative Wildlife Disease Study, University of Georgia, for guidance on testing for DEV, and Stephen Spatz and Teresa Ross for providing DEV-positive control for DEV molecular testing. Finally, we thank Christina Leyson for critical review of this manuscript. Mention of trade names or commercial products does not imply recommendation or endorsement by the U.S. Department of Agriculture. Any use of trade, firm, or product names is for descriptive purposes only and does not imply endorsement by the U.S. Government. All opinions expressed in this paper are the authors' and do not necessarily reflect the policies and views of U.S. Department of Agriculture, Agriculture Research Service, U.S. Department of Energy, or Oak Ridge Associated Universities/Oak Ridge Institute for Science and Education. The U.S. Department of Agriculture is an equal opportunity provider and employer.

\section{Authors' contributions}

ES, DP, MPJ and ACB conceived and designed experiments. ES performed animal experiments. JML performed data analysis and drafted manuscript. MPJ performed histopathological analyses. ACB, DP, ES, JML, and MPJ reviewed and edited the manuscript. All authors have read and approved the manuscript.

\section{Funding}

This research was supported by U.S. Department of Agriculture -Agricultural Research Service project 6040-32000-066-00D and U.S. Department of Agriculture -Animal and Plant Health Inspection Service Agreement \#606040-6-005. This research was supported in part by an appointment to the Agricultural Research Service Research Participation Program administered by the Oak Ridge Institute for Science and Education through an interagency agreement between the U.S. Department of Energy and the U.S. Department of Agriculture. Oak Ridge Institute for Science and Education is managed by Oak Ridge Associated Universities under U.S. Department of Energy contract number DE-SC0014664. Funding bodies had no involvement in study design, data collection and analysis, decision to publish, or preparation of the manuscript.

\section{Availability of data and materials}

The datasets used and/or analysed during the current study are available from the corresponding author on reasonable request.

\section{Ethics approval and consent to participate}

All animal research was reviewed and approved by the U.S. National Poultry Research Center Institutional Animal Care and Use Committee. Scoter captivity and transport to Southeast Poultry Research Laboratory was approved by the U.S. Geological Survey Patuxent Wildlife Research Center Animal Care and Use Committee. Animal studies adhered to the Federation of Animal Science Societies Guide for the Care and Use of Agricultural Animals in Research and Training. Institutional review board review does not apply because the ducks are owned by the US government and approval by the IACUC is considered consent to use the ducks. Humane euthanasia of birds was performed according to American Veterinary Medical Association (AVMA) guidelines: intravenous injection of $0.2 \mathrm{~mL}$ per $\mathrm{Kg}$ of pentobarbiotal sodium solution (Fatal-Plus, Vortech Pharmaceuticals, Dearborn, MI) without sedation. This method was utilized because it was the AVMA recommended method which was reviewed and approved by the USNPRC IACUC.

\section{Consent for publication}

Not applicable.

Competing interests

The authors declare that they have no competing interests. 


\section{Author details}

'Department of Agriculture-Agricultural Research Service, Southeast Poultry Research Laboratory, U.S. National Poultry Research Center, U.S., 934 College Station Road, Athens, GA 30605, USA. ${ }^{2}$ US Geological Survey, Patuxent Wildlife Research Center, 12100 Beech Forest Road, Laurel, MD 20708, USA.

Received: 14 April 2020 Accepted: 17 September 2020

Published online: 23 September 2020

\section{References}

1. Webster RG, Bean WJ, Gorman OT, Chambers TM, Kawaoka Y. Evolution and ecology of influenza a viruses. Microbiol Rev. 1992;56(1):152-79.

2. World Organisation for Animal Health (OIE). Avian Influenza. In: Terrestial animal health code. vol. 2, 20th edn: World Organisation for Animal Health (OIE); 2011. p. 1-18.

3. CDC. Biosafety recommendations for work with influenza viruses containing a hemagglutinin from the A/goose/Guangdong/1/96 lineage. MMWR Recomm Rep. 2013;62(6):1-7.

4. Hulse-Post DJ, Sturm-Ramirez KM, Humberd J, Seiler P, Govorkova EA, Krauss S, Scholtissek C, Puthavathana P, Buranathai C, Nguyen TD, et al. Role of domestic ducks in the propagation and biological evolution of highly pathogenic H5N1 influenza viruses in Asia. Proc Natl Acad Sci U S A. 2005; 102(30):10682-7

5. Sturm-Ramirez KM, Hulse-Post DJ, Govorkova EA, Humberd J, Seiler P, Puthavathana P, Buranathai C, Nguyen TD, Chaisingh A, Long HT, et al. Are ducks contributing to the endemicity of highly pathogenic $\mathrm{H} 5 \mathrm{~N} 1$ influenza virus in Asia? J Virol. 2005;79(17):11269-79.

6. Tumpey TM, Suarez DL, Perkins LEL, Senne DA, Lee J-G, Lee Y-J, Mo I-P, Sung H-W, Swayne DE. characterization of a highly pathogenic H5N1 avian influenza a virus isolated from duck meat. J Virol. 2002;76(12):6344-55.

7. Chen H, Deng G, Li Z, Tian G, Li Y, Jlao P, Zhang L, Liu Z, Webster RG, Yu K. The evolution of H5N1 influenza viruses in ducks in southern China. Proc Natl Acad Sci U S A. 2004;101(28):10452-7.

8. Keawcharoen J, van Riel D, van Amerongen G, Bestebroer T, Beyer WE, van Lavieren R, Osterhaus ADME, Kuiken T. Wild ducks as long-distance vectors of highly pathogenic avian influenza virus (H5N1). Emerg Infect Dis. 2008; 14(4):600-7.

9. Wibawa H, Bingham J, Nuradji H, Lowther S, Payne J, Harper J, Wong F, Lunt $\mathrm{R}$, Junaidi A, Middleton $\mathrm{D}$, et al. The pathobiology of two Indonesian H5N1 avian influenza viruses representing different clade 2.1 sublineages in chickens and ducks. Comp Immunol Microbiol Infect Dis. 2013;36(2):175-91.

10. Fourment $M$, Darling $A E$, Holmes EC. The impact of migratory flyways on the spread of avian influenza virus in North America. BMC Evol Biol. 2017; 17(1):118

11. Pasick J, Berhane Y, Joseph T, Bowes V, Hisanaga T, Handel K, Alexandersen S. Reassortant highly pathogenic influenza a $\mathrm{H} 5 \mathrm{~N} 2$ virus containing gene segments related to Eurasian H5N8 in British Columbia, Canada, 2014. Sci Rep. 2015;5:9484.

12. Nazir J, Haumacher R, Ike A, Stumpf P, Böhm R, Marschang RE. Long-term study on tenacity of avian influenza viruses in water (distilled water, normal saline, and surface water) at different temperatures. Avian Dis. 2010;54(s1): 720-4 725.

13. Keeler SP, Dalton MS, Cressler AM, Berghaus RD, Stallknecht DE. Abiotic factors affecting the persistence of avian influenza virus in surface waters of waterfowl habitats. Appl Environ Microbiol. 2014:80(9):2910-7.

14. Surveillance plan for highly pathogenic avian influenza in wild migratory birds in the United States. https://www.aphis.usda.gov/animal_health/ downloads/animal_diseases/ai/2017-hpai-surveillance-plan.pdf. Accessed 22 Aug 2019.

15. Hall JS, Russell RE, Franson JC, Soos C, Dusek RJ, Allen RB, Nashold SW, TeSlaa JL, Jónsson JE, Ballard JR, et al. Avian influenza ecology in North Atlantic Sea ducks: not all ducks are created equal. PLoS One. 2015;10(12): e0144524.

16. Wilson HM, Hall JS, Flint PL, Franson JC, Ely CR, Schmutz JA, Samuel MD. High seroprevalence of antibodies to avian influenza viruses among wild waterfowl in Alaska: implications for surveillance. PLoS One. 2013;8(3): e58308

17. Ramey AM, Reeves AB, Poulson RL, Wasley J, Esler D, Stallknecht DE. Sampling of sea ducks for influenza a viruses in Alaska during winter provides lack of evidence for epidemiologic peak of infection. J Wildl Dis. 2015;51(4):938-41 934.
18. Nolting J, Fries AC, Slemons RD, Courtney C, Hines N, Pedersen J. Recovery of H14 influenza a virus isolates from sea ducks in the Western hemisphere. PLoS Curr. 2012:4:RRN1290.

19. Xu Y, Ramey AM, Bowman AS, DeLiberto TJ, Killian ML, Krauss S, Nolting JM, Torchetti MK, Reeves AB, Webby RJ, et al. Low-pathogenic influenza a viruses in north American diving ducks contribute to the emergence of a novel highly pathogenic influenza a(H7N8) virus. J Virol. 2017;91(9):e02208-16.

20. Spackman E, Prosser DJ, Pantin-Jackwood MJ, Berlin AM, Stephens CB. The pathogenesis of clade 2.3.4.4 H5 highly pathogenic avian influenza viruses in Ruddy duck (Oxyura jamaicensis) and lesser Scaup (Aythya affinis). J Wildl Dis. 2017;53(4):832-42.

21. Stephens CB, Prosser DJ, Pantin-Jackwood MJ, Berlin AM, Spackman E. The pathogenesis of $\mathrm{H7}$ highly pathogenic avian influenza viruses in Lesser Scaup (Aythya affinis). Avian Diseases. 2019;63(sp1):230-4.

22. van den Brand JMA, Verhagen JH, Veldhuis Kroeze EJB, van de Bildt MWG, Bodewes R, Herfst S, Richard M, Lexmond P, Bestebroer TM, Fouchier RAM, et al. Wild ducks excrete highly pathogenic avian influenza virus H5N8 (2014-2015) without clinical or pathological evidence of disease. Emerg Microbes Infect. 2018;7(1):1-10.

23. Brown JD, Stallknecht DE, Beck JR, Suarez DL, Swayne DE. Susceptibility of North American ducks and gulls to H5N1 highly pathogenic avian influenza viruses. Emerg Infect Dis. 2006;12(11):1663-70.

24. Surf scoter (Melanitta perspicillata). https://www.audubon.org/field-guide/ bird/surf-scoter. Accessed 23 July 2019.

25. Baccam P, Beauchemin C, Macken CA, Hayden FG, Perelson AS. Kinetics of influenza a virus infection in humans. J Virol. 2006;80(15):7590-9.

26. Löndt BZ, Núñez A, Banks J, Alexander DJ, Russell C, Richard-Löndt AC, Brown $\mathrm{H}$. The effect of age on the pathogenesis of a highly pathogenic avian influenza (HPAI) H5N1 virus in Pekin ducks (Anas platyrhynchos) infected experimentally. Influenza Other Respir Viruses. 2010;4(1):17-25.

27. Pantin-Jackwood MJ, Costa-Hurtado M, Shepherd E, DeJesus E, Smith D, Spackman E, Kapczynski DR, Suarez DL, Stallknecht D, Swayne DE. Pathogenicity and transmission of $\mathrm{H} 5$ and $\mathrm{H} 7$ highly pathogenic avian influenza viruses in mallards. J Virol. 2016;90(21):9967-82.

28. DeJesus E, Costa-Hurtado M, Smith D, Lee D-H, Spackman E, Kapczynski DR, Torchetti MK, Killian ML, Suarez DL, Swayne DE, et al. Changes in adaptation of H5N2 highly pathogenic avian influenza $\mathrm{H} 5$ clade 2.3.4.4 viruses in chickens and mallards. Virology. 2016;499:52-64.

29. Metwally SA. Duck Virus Enteritis (Duck Plague). In: Swayne DE, Glisson JR, LR MD, Nolan LK, Suarez DL, Ames NV, editors. Diseases of Poultry. 13th edn edn. lowa: Wiley; 2013. p. 431-40.

30. Antigenic and genetic characteristics of zoonotic influenza viruses and development of candidate vaccine viruses for pandemic preparedness. https://www.who.int/influenza/vaccines/virus/201902_zoonotic vaccinevirusupdate.pdf?ua=1. Accessed 25 Mar 201.

31. The Global Consortium for H5N8 and Related Influenza Viruses. Role for migratory wild birds in the global spread of avian influenza H5N8. Science. 2016:354(6309):213-7.

32. de Vries E, Guo H, Dai M, Rottier PJM, van Kuppeveld FJM, de Haan CAM. Rapid emergence of highly pathogenic avian influenza subtypes from a subtype H5N1 hemagglutinin variant. Emerg Infect Dis. 2015;21(5):842-6.

33. Zhao K, Gu M, Zhong L, Duan Z, Zhang Y, Zhu Y, Zhao G, Zhao M, Chen Z, Hu $\mathrm{S}$, et al. Characterization of three H5Ns5 and one H5N8 highly pathogenic avian influenza viruses in China. Vet Microbiol. 2013;163(3):351-7.

34. Liu C-G, Liu M, Liu F, Lv R, Liu D-F, Qu L-D, Zhang Y. Emerging multiple reassortant H5N5 avian influenza viruses in ducks, China, 2008. Vet Microbiol. 2013;167(3):296-306.

35. Lee $Y-J$, Kang H-M, Lee E-K, Song B-M, Jeong J, Kwon Y-K, Kim H-R, Lee K-J, Hong M-S, Jang I, et al. Novel reassortant influenza a(H5N8) viruses, South Korea, 2014. Emerg Infect Dis. 2014;20(6):1087-9.

36. Kanehira K, Uchida Y, Takemae N, Hikono H, Tsunekuni R, Saito T. Characterization of an H5N8 influenza a virus isolated from chickens during an outbreak of severe avian influenza in Japan in April 2014. Arch Virol. 2015;160(7):1629-43.

37. Ku KB, Park EH, Yum J, Kim JA, Oh SK, Seo SH. Highly pathogenic avian influenza a(H5N8) virus from waterfowl, South Korea, 2014. Emerg Infect Dis. 2014;20(9):1587-8

38. Marchenko WY, Susloparov IM, Kolosova NP, Goncharova NI, Shipovalov AV, Durymanov AG, Ilyicheva TN, Budatsirenova LV, Ivanova VK, Ignatyev GA et al. Influenza a(H5N8) virus isolation in Russia, 2014. Arch Virol. 2015. 160(11):2857-60. 
39. Harder T, Maurer-Stroh S, Pohlmann A, Starick E, Höreth-Böntgen D, Albrecht K, Pannwitz G, Teifke JP, Gunalan V, Lee RTC, et al. Influenza a(H5N8) virus similar to strain in Korea causing highly pathogenic avian influenza in Germany. Emerg Infect Dis. 2015;21(5):860-3.

40. Hanna A, Banks J, Marston DA, Ellis RJ, Brookes SM, Brown IH. Genetic characterization of highly pathogenic avian influenza ( $\mathrm{H} 5 \mathrm{~N} 8$ ) virus from domestic ducks, England, November 2014. Emerg Infect Dis. 2015;21(5):879.

41. Update on avian influenza in animals (types $\mathrm{H} 5$ and $\mathrm{H} 7$ ). https://www.oie. int/animal-health-in-the-world/update-on-avian-influenza/2014/. Accessed 28 Dec 2019.

42. Update on avian influenza in animals (types $\mathrm{H} 5$ and H7). https://www.oie. int/animal-health-in-the-world/update-on-avian-influenza/2015/. Accessed 28 Dec 2019.

43. Ip HS, Torchetti MK, Crespo R, Kohrs P, DeBruyn P, Mansfield KG, Baszler T, Badcoe L, Bodenstein B, Shearn-Bochsler V, et al. Novel Eurasian highly pathogenic avian influenza a H5 viruses in wild birds, Washington, USA, 2014. Emerg Infect Dis. 2015;21(5):886-90.

44. Lee D-H, Bahl J, Torchetti MK, Killian ML, Ip HS, DeLiberto TJ, Swayne DE. Highly pathogenic avian influenza viruses and generation of novel reassortants, United States, 2014-2015. Emerg Infect Dis. 2016;22(7):1283-5.

45. Lee D-H, Torchetti MK, Killian ML, TJ DL, Swayne DE. Reoccurrence of avian influenza a(H5N2) virus clade 2.3.4.4 in wild birds, Alaska, USA, 2016. Emerg Infect Dis. 2017;23(2):365-7.

46. Yamaji R, Saad MD, Davis CT, Swayne DE, Wang D, Wong FYK, McCauley JW, Peiris JSM, Webby RJ, Fouchier RAM, et al. Pandemic potential of highly pathogenic avian influenza clade 2.3.4.4 A(H5) viruses. Rev Med Virol. 2020; 30(3):e2099.

47. Kwon J-H, Lee D-H, Swayne DE, Noh J-Y, Yuk S-S, Erdene-Ochir T-O, Hong W-T, Jeong J-H, Jeong S, Gwon G-B, et al. Highly pathogenic avian influenza $\mathrm{a}(\mathrm{H} 5 \mathrm{~N} 8)$ viruses reintroduced into South Korea by migratory waterfowl, 2014-2015. Emerg Infect Dis. 2016;22(3):507-10.

48. Jeong J, Kang H-M, Lee E-K, Song B-M, Kwon Y-K, Kim H-R, Choi K-S, Kim J$\mathrm{Y}$, Lee $\mathrm{H}-J$, Moon O-K, et al. Highly pathogenic avian influenza virus (H5N8) in domestic poultry and its relationship with migratory birds in South Korea during 2014. Vet Microbiol. 2014;173(3):249-57.

49. Alexander DJ, Parsons G, Manvell RJ. Experimental assessment of the pathogenicity of eight avian influenza a viruses of H5 subtype for chickens, turkeys, ducks and quail. Avian Pathol. 1986;15(4):647-62.

50. Webster RG, Yakhno M, Hinshaw VS, Bean WJ, Murti KG. Intestinal influenza: replication and characterization of influenza viruses in ducks. Virology. 1978; 84(2):268-78.

51. Kida H, Yanagawa R, Matsuoka Y. Duck influenza lacking evidence of disease signs and immune response. Infect Immun. 1980;30(2):547-53.

52. Germeraad EA, Sanders P, Hagenaars TJ, de Jong MCM, Beerens N, Gonzales $J$. Virus shedding of avian influenza in poultry: a systematic review and meta-analysis. Viruses. 2019;11(9):812.

53. Hénaux V, Samuel MD. Avian influenza shedding patterns in waterfowl: implications for surveillance, environmental transmission, and disease spread. J Wildl Dis. 2011:47(3):566-78.

54. European Food Safety Authority (EFSA), European Centre for Disease Prevention and Control (ECDC), European Union Reference Laboratory for Avian influenza (EURL), Brown I, Kuiken T, Mulatti P, Smietanka K, Staubach C, Stroud D, Therkildsen OR, et al. Avian influenza overview September November 2017. EFSA J. 2017;15(12):e05141.

55. Tufted duck (Aythya fuligula). https://www.audubon.org/field-guide/bird/ tufted-duck. Accessed 29 Dec 2019.

56. Bröjer C, Ågren EO, Uhlhorn H, Bernodt K, Mörner T, Jansson DS, Mattsson R Zohari S, Thorén P, et al. Pathology of natural highly pathogenic avian influenza H5N1 infection in wild tufted ducks (Aythya Fuligula). J Vet Diagn Investig. 2009;21(5):579-87.

57. Kleyheeg E, Slaterus R, Bodewes R, Rijks JM, Spierenburg MAH, Berrens N, Kelder L, Poen MJ, Stegeman JA, Fouchier RAM, et al. Deaths among wild birds during highly pathogenic avian influenza a(H5N8) virus outbreak, the Netherlands. Emerg Infect Dis. 2017;23(12):2050-4.

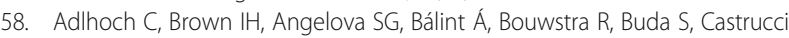
MR, Dabrera G, Dán Á, Grund C, et al. Highly pathogenic avian influenza a(H5N8) outbreaks: protection and management of exposed people in Europe, 2014/15 and 2016. Eurosurveillance. 2016;21(49):30419.

59. Bröjer $C$, van Amerongen $G$, van de Bildt M, van Run P, Osterhaus A, GavierWidén D, Kuiken T. Pathogenicity and tissue tropism of currently circulating highly pathogenic avian influenza a virus (H5N1; clade 2.3.2) in tufted ducks (Aythya fuligula). Vet Microbiol. 2015;180(3):273-80.

60. Srivastava B, Błazejewska P, Hessmann M, Bruder D, Geffers R, Mauel S, Gruber AD, Schughart K. Host genetic background strongly influences the response to influenza a virus infections. PLoS One. 2009;4(3):e4857.

61. Boon ACM, Finkelstein D, Zheng M, Liao G, Allard J, Klumpp K, Webster R, Peltz G, Webby RJ. H5N1 influenza virus pathogenesis in genetically diverse mice is mediated at the level of viral load. mBio. 2011;2(5):e00171-11.

62. Gough RE. Duck virus enteritis. In: Pattison M, PF MM, Bradbury JM, Alexander DJ, editors. Poultry Diseases. 6th edn edn. Philadelphia: Saunders Elsevier; 2008. p. 272-5.

63. Campagnolo ER, Banerjee M, Panigrahy B, Jones RL. An outbreak of duck viral enteritis (duck plague) in domestic muscovy ducks (Cairina moschata domesticus) in Illinois. Avian Dis. 2001;45(2):522-8.

64. Shawky S, Schat KA. Latency sites and reactivation of duck enteritis virus. Avian Dis. 2002;46(2):308-13.

65. Bertran K, Swayne DE, Pantin-Jackwood MJ, Kapczynski DR, Spackman E, Suarez DL. Lack of chicken adaptation of newly emergent Eurasian H5N8 and reassortant H5N2 high pathogenicity avian influenza viruses in the U.S. is consistent with restricted poultry outbreaks in the Pacific flyway during 2014-2015. Virology. 2016;494:190-7.

66. Spackman E, Pantin-Jackwood MJ, Kapczynski DR, Swayne DE, Suarez DL. H5N2 highly pathogenic avian influenza viruses from the US 2014-2015 outbreak have an unusually long pre-clinical period in turkeys. BMC Vet Res. 2016;12(1):260.

67. Reed $\amalg$, Muench $\mathrm{H}$. A simple method for estimating fifty per cent endpoints. Am J Epidemiol. 1938;27(3):493-7.

68. Spackman E, Gelb J Jr, Preskenis LA, Ladman BS, Pope CR, Pantin-Jackwood MJ, McKinley ET. The pathogenesis of low pathogenicity $\mathrm{H} 7$ avian influenza viruses in chickens, ducks and turkeys. Virol J. 2010;7:331.

69. Pantin-Jackwood MJ, Swayne DE. Pathobiology of asian highly pathogenic avian influenza H5N1 virus infections in ducks. Avian Dis. 2007;51(1 Supplement: Six International Symposia on Avian Influenza):250-9..

70. Pederson JC. Hemagglutination-inhibition assay for influenza virus subtype identification and the detection and quantitation of serum antibodies to influenza virus. In: Spackman E, editor. Animal Influenza Virus. 2nd edn edn. New York: Humana Press; 2014. p. 11-25.

71. Das A, Spackman E, Pantin-Jackwood MJ, Suarez DL. Removal of real-time reverse transcription polymerase chain reaction (RT-PCR) inhibitors associated with cloacal swab samples and tissues for improved diagnosis of avian influenza virus by RT-PCR. J Vet Diagn Investig. 2009;21(6):771-8.

72. Spackman E, Senne DA, Myers TJ, Bulaga LL, Garber LP, Perdue ML, Lohman K, Daum LT, Suarez DL. Development of a real-time reverse transcriptase PCR assay for type a influenza virus and the avian $\mathrm{H} 5$ and $\mathrm{H} 7$ hemagglutinin subtypes. J Clin Microbiol. 2002;40(9):3256-60.

73. Hansen WR, Nashold SW, Docherty DE, Brown SE, Knudson DL. Diagnosis of duck plague in waterfowl by polymerase chain reaction. Avian Dis. 2000; 44(2):266-74.

\section{Publisher's Note}

Springer Nature remains neutral with regard to jurisdictional claims in published maps and institutional affiliations.

Ready to submit your research? Choose BMC and benefit from:

- fast, convenient online submission

- thorough peer review by experienced researchers in your field

- rapid publication on acceptance

- support for research data, including large and complex data types

- gold Open Access which fosters wider collaboration and increased citations

- maximum visibility for your research: over $100 \mathrm{M}$ website views per year

At $\mathrm{BMC}$, research is always in progress.

Learn more biomedcentral.com/submission 